\title{
Produção de mudas de Aloysia gratissima (Gillies \& Hook.) Tronc. por meio da propagação sexuada e assexuada
}

\author{
SANTOS, F.M. ${ }^{1}$; PINTO, J.E.B.P. ${ }^{2}$; ALVARENGA, A.A. ${ }^{1}$; OLIVEIRA, J.A. ${ }^{2}$; OLIVEIRA, A.A. ${ }^{2}$; OLIVEIRA, L.P. ${ }^{2}$ \\ ${ }^{1}$ Departamento de Biologia/Fisiologia Vegetal. ${ }^{2}$ Departamento de Agricultura, Universidades Federal de Lavras \\ (UFLA). Caixa Postal 3037, CEP 37200-000, Lavras, MG, Brasil. *jeduardo@ufla.br
}

\begin{abstract}
RESUMO: A alfazema-do-Brasil é planta de importância medicinal, como produtora de terpenos. A principal descrição etnofarmaco-botânica aponta como sendo eficaz para infecções brônquicas, pulmonares e da bexiga. $O$ objetivo do trabalho foi estudar a propagação de $A$. gratissima visando a obtenção de mudas. Na propagação sexuada estudou-se a influência da temperatura na presença e ausência de luz e três épocas de coleta das sementes (março, junho e setembro). Na propagação via semente foram testados três diferentes substratos (areia, palha de arroz carbonizada, Plantmax ${ }^{\circledR}$ ). Na propagação vegetativa foram testados dois tipos de estacas (herbáceas e semilenhosas) e de dois substratos (areia e Plantmax ${ }^{\circledR}$ ). Os resultados indicaram que na propagação sexuada, a germinação das sementes foi maior nas temperaturas constantes de 20 e $25^{\circ} \mathrm{C}$, e a melhor época de coleta de sementes foi em março. O substrato comercial mostrou-se superior para o crescimento das plântulas, atingindo $93,25 \%$ de emergência das sementes e $100 \%$ de sobrevivência. Para a propagação assexuada, as estacas herbáceas em substrato comercial e areia apresentaram 96 e $95 \%$ de enraizamento, respectivamente.
\end{abstract}

Palavras-chave: Verbenaceae, substrato, germinação, estaquia

\begin{abstract}
Aloysia gratissima (Gillies \& Hook.) Tronc. seedling production through sexual and asexual propagation. Brazilian-lavender is a medicinally important plant since it produces terpenes. As regards ethnopharmacology, it is mainly efficient against bronchial, lung and bladder infections. The aim of this work was to study Aloysia gratissima propagation for seedling production. In sexual propagation, temperature influence in the presence and absence of light and three seed harvesting times (March, June, and September) were studied. Three different substrates (sand, carbonized rice husk, Plantmax ${ }^{\circledR}$ ) were also evaluated for seed germination. In vegetative propagation, two cutting types (herbaceous and semihardwood) and two substrates (sand, Plantmax ${ }^{\circledR}$ ) were tested. Seed germination was higher under constant temperatures of 20 and $25^{\circ} \mathrm{C}$, and March was the best seed harvest time for sexual propagation. The commercial substrate was the best for seedling growth, peaking $93.25 \%$ seedling emergency and $100 \%$ survival. For asexual propagation, herbaceous cuttings in the commercial substrate and sand presented $96 \%$ and $95 \%$ rooting, respectively.
\end{abstract}

Key words: Verbenaceae, substrate, germination, cutting

\section{INTRODUÇÃO}

Aloysia gratissima (Gillies \& Hook.) Tronc. [Verbenaceae] popularmente denominada de alfazema-do-brasil, é um arbusto de até 3 metros de altura, muito ramificado e espinescente nos ápices (Pinto et al., 2007). As folhas e ramos são usados para preparo de expectorantes, e a principal descrição etnofarmaco-botânica relata a eficácia em infecções brônquicas, afecções pulmonares, além de possuir ação antimicrobiana (Pinto et al., 2007).

Devido as propriedades medicinais, esta espécie vem sendo muito difundida na medicina popular sul-americana (Souza et al., 2007), sendo que o interesse no estudo da propagação, se deve ao fato de que as populações naturais vêm diminuindo em conseqüência do desmatamento.

Há vários fatores que podem influenciar a

Recebido para publicação em 05/12/2007

Aceito para publicação em 21/08/2008

Rev. Bras. PI. Med., Botucatu, v.11, n.2, p.130-136, 2009. 
propagação sexuada e assexuada. A disponibilidade de água e temperatura apropriadas são fatores extrínsecos fundamentais para ocorrer o inicio do processo germinativo (Baskin \& Baskin, 2001), enquanto as necessidades de luz e nutrientes estão relacionadas às características particulares de cada espécie (Silva, 2005).

A utilização de substrato, tanto na propagação sexuada como na assexuada (estaquia), tem sido alternativa aos problemas causados pelo cultivo tradicional em solo, devido à proliferação de patógenos, salinização de solos, otimização do uso efetivo de água e a exigência do consumidor quanto a sistemas de produção menos agressivos ao meio ambiente (Bezerra \& Ledderman, 1995).

Além da propagação sexuada, o estudo do comportamento da espécie frente a produção de mudas via estacas se faz necessário, onde o plantio de estacas herbáceas, semilenhosas e lenhosas, com folha presente ou ausente, assim como as épocas de coleta do material influenciam consideravelmente no enraizamento (Bezerra \& Ledderman, 1995; Hartmann et al., 2002).

O objetivo do presente trabalho foi desenvolver protocolos que permitam maximizar a germinação de sementes e a rizogênese de estacas de $A$. gratissima visando a produção de mudas, no sentido de melhorar a sua produção.

\section{MATERIAL E MÉTODO}

Para propagação sexuada, as sementes foram coletadas na época de dispersão, que ocorre entre março a setembro. Para propagação assexuada selecionou-se material (estacas) a partir de plantas matrizes de três anos de idade, em outubro de 2006, do Horto Medicinal - DAG - UFLA. A exsicata está depositada no herbário da Universidade Federal de Lavras, sob o registro ESAL 19810.

O peso médio de mil sementes foi determinado utilizando-se oito sub-amostras com 100 unidades pesadas em balança analítica e para a determinação do tamanho médio, foram realizadas 05 amostras com 100 sementes medidas com paquímetro mediante auxilio de lupa (Brasil, 1992).

\section{Propagação sexuada - germinação}

Para o teste de germinação, as sementes foram submetidas a diferentes regimes térmicos com temperaturas constantes de 20,25 e $30^{\circ} \mathrm{C}$ e temperatura alternada $20^{\circ} \mathrm{C}-30^{\circ} \mathrm{C} \pm 2^{\circ} \mathrm{C}$, com tempo de alternância de 12 horas; na presença e ausência de luz, com fotoperíodo de 12 horas em câmara de germinação do tipo BOD com UR de $100 \%$. A condição de escuro foi alcançada pelo envolvimento das caixas tipo gerbox com folha dupla de papel alumínio. Como substrato, foram utilizadas duas folhas de papel mata- borrão, com umidade de 2,5 vezes o peso do papel seco. Utilizaram-se quatro repetições de 100 sementes para cada tratamento. Em estudos prévios, verificou-se não ser necessário retirar o tegumento das sementes.

Para o cálculo de percentagem de germinação das sementes, o critério de avaliação utilizado foi a protrusão radicular. As avaliações foram efetuadas diariamente, sendo que, para os tratamentos sem luz, estes foram realizados em ambiente reservado sob luz verde. Para todos os testes foram realizados testes de tetrazólio a $1 \%$ para avaliar a viabilidade das sementes não germinadas (Brasil, 1992).

\section{Determinação da época de coleta de sementes}

Foram avaliadas três épocas de coletas de sementes (março, junho e setembro de 2006), caracterizando o início, meio e fim da época de dispersão. Cada época foi composta de quatro repetições com 100 sementes. As condições de germinação foram a $25^{\circ} \mathrm{C}$ em câmara de germinação do tipo BOD com fotoperíodo de $12 \mathrm{~h}$, na presença de luz.

\section{Determinação de substrato para germinação de sementes e desenvolvimento de plântulas}

$O$ experimento foi conduzido em casa-devegetação. Os substratos foram areia lavada e esterilizada, casca de arroz carbonizada e substrato comercial (Plantmax ${ }^{\circledR}$ Hortaliças). As avaliações de germinação (emergência) foram realizadas diariamente, utilizando-se como parâmetro de emergência a protrusão da plântula, até a estabilização de emergência, sendo analisados o percentual de emergência.

Após 35 dias, foram avaliados os fatores de crescimento: número de par de folhas, comprimento médio de folha (par) do segundo nó, comprimento do ramo e comprimento da raiz principal, transferindose 100 plântulas de cada substrato para copos de plástico com capacidade de $200 \mathrm{~mL}$, preenchidos com substrato o comercial (Plantmax ${ }^{\circledR}$ Hortaliças). Com trinta dias após o transplante, verificou-se a taxa de sobrevivência das plantas para cada tratamento.

Para a determinação do melhor substrato para germinação, o delineamento experimental utilizado foi inteiramente casualizado (DIC), em sementeira com 128 células para cada substrato, com quatro repetições de 32 células para a emergência e cinco repetições de 10 plântulas para análise de crescimento. Para a análise de sobrevivência utilizaram-se quatro repetições de 25 plântulas cada.

Os dados obtidos para a propagação sexuada foram analisados pelo software estatístico SISVAR 4.3, sendo as médias entre os tratamentos comparados pelo teste $F$ (Tukey) a $5 \%$ de 
significância, num delineamento inteiramente casualizado (Ferreira, 1999).

\section{Propagação assexuada (estaquia)}

De quatro plantas matrizes com três anos de idade, foram retiradas estacas herbáceas e semilenhosas com $15 \mathrm{~cm}$ de comprimento com quatro pares de folhas. Como substratos foram utilizados areia lavada e substrato comercial (Plantmax ${ }^{\circledR}$ Hortaliças), num fatorial $2 \times 2$ (tipos de estacas $x$ substratos) e avaliados após 35 dias. As variáveis analisadas foram percentagem de enraizamento, comprimento, número e biomassa seca da raiz. Utilizaram-se seis repetições de 10 plantas por unidade experimental. Os dados obtidos foram analisados no software estatístico SISVAR 4.3 pelo teste $\mathrm{F}$ (Scott-Knott) a 5\% de significância (Ferreira, 1999).

\section{RESULTADOE DISCUSSÃO}

\section{Característica física das sementes de alfazema-do-brasil \\ As sementes de $A$. gratissima são} pequenas, possuindo aproximadamente $0,2 \mathrm{~mm}$ de comprimento e $0,29 \mathrm{mg}$ semente ${ }^{-1}$, biloculadas, envoltas por casca pilosa, com embrião protegido por uma casca dura. De acordo com as Regras para Análise de Sementes (RAS) (Brasil, 1992), a massa de mil sementes (PMS) é usada para estimar o número de sementes por grama, então, um PMS igual a 0,29 g permite estimar que um grama de sementes de $A$. gratissima possui aproximadamente 3.448 unidades. Este dado permite calcular a densidade de semeadura, principalmente em se tratando de sementes pequenas, com dificuldade de se efetuar a contagem.

Conforme Baskin \& Baskin (2001), a produção de grande número de sementes por algumas espécies, como as de $A$. gratissima é uma estratégia biológica que visa aumentar a probabilidade de algumas destas alcançarem os sítios favoráveis à germinação ou permanecerem dormentes no solo, aguardando o momento propício para sua germinação e estabelecimento.

\section{Propagação sexuada - germinação}

Os resultados mostraram que na presença de luz, os tratamentos a 20 e $25^{\circ} \mathrm{C}$ apresentaram um índice de germinação de 91,5 e $94,75 \%$, respectivamente, enquanto na ausência da luz com temperaturas de 20 e $25^{\circ} \mathrm{C}$ ocorreu um índice de germinação de 5 e 29,5\%, respectivamente (Figura 1). Temperaturas mais altas ou alternadas na presença de luz apresentaram 37,25 e 54,5\%, respectivamente, evidenciando que as sementes de
A. gratissima necessitam de temperaturas mais baixas e mostram predomínio de fotoblastismo positivo para germinar. Agerminação rápida é desejável para as espécies cultivadas, mostrando seu vigor ante as condições do meio ambiente. Assim sendo, as sementes permanecem menos tempo sujeitas às condições adversas para o estabelecimento no campo. Para todas as sementes não germinadas foi efetuado o teste de tetrazólio a $1 \%$, observando-se que as sementes estavam viáveis, havendo provavelmente algum efeito de dormência.

Rosa \& Ferreira (2001), trabalhando com $A$. gratissima, encontraram melhores resultados em temperaturas alternantes $\left(20-30^{\circ} \mathrm{C}\right)$, com $44 \%$ de germinação em caixas tipo gerbox com areia. No referido trabalho, a presença de luz ou ausência de luz foi indiferente (fotoblásticas neutras), fato que discorda dos resultados obtidos no presente estudo. Nos resultados encontrados em temperatura alternada de $20-30^{\circ} \mathrm{C}$ a germinabilidade foi de $54,50 \%$ (Figura 1 ), aproximando-se dos resultados encontrados pelos pesquisadores supracitados.

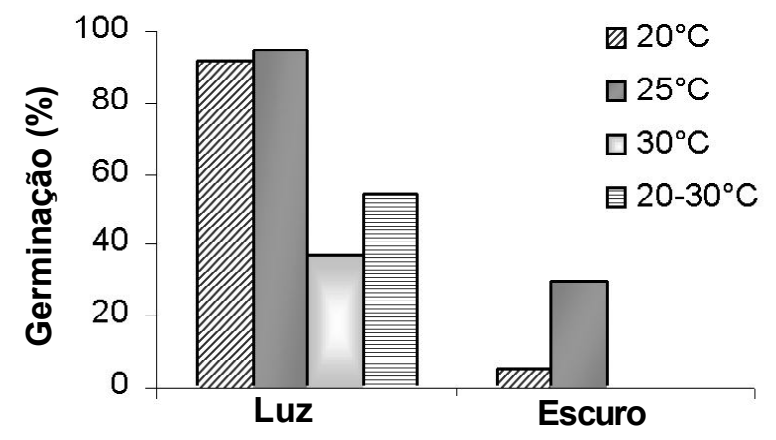

FIGURA 1. Valores médios de percentagem de germinação de sementes de $A$. gratissima submetidos a quatro temperaturas e na presença $(L)$ e ausência de luz (E), colhidas em março de 2006.

**Médias seguidas da mesma letra maiúscula (luz e escuro) e minúscula (temperaturas), não diferem estatisticamente entre si, pelo teste $F$ (Tukey) $(p<0,05)$. Teste de Tetrazólio $(T Z)>$ $90 \%$.

Época de coleta de sementes de $A$. gratissima A época de coleta de sementes de $A$. gratissima interfere significativamente na germinabilidade da mesma (Figura 2). Na primeira coleta em março, as sementes apresentaram $95 \%$ de germinação, por outro lado, as provenientes da última coleta em setembro, apresentaram $5 \%$ de germinação. As sementes oriundas da coleta intermediária, feita em junho, apresentaram 49,75\% de germinação, sendo o resultado que mais se aproxima do valor encontrado por Rosa \& Ferreira (2001), ou seja, com 44\% de germinação, com temperatura alternada de $20-30^{\circ} \mathrm{C}$.

Observa-se com o teste de tetrazólio a 1\% 
que as sementes não germinadas estavam viáveis. O que pode estar ocorrendo é provável dormência das mesmas, em conseqüência da época de coleta.

\section{Determinação de substrato para germinação de sementes e desenvolvimento de plântulas}

A percentagem de germinação de sementes foi influenciada pelo tipo de substrato utilizado (Tabela 1). Os substratos diferem quanto às características de umidade, capacidade de retenção de água, interferindo na germinação de sementes de $A$. gratissima.

Os maiores resultados de germinação para propagação sexuada de $A$. gratissima foram com os substratos casca de arroz carbonizada (95,50\%), que não diferiu estatisticamente do substrato comercial $(93,25)$, os menores resultados foram obtidos com areia $(87 \%)$.

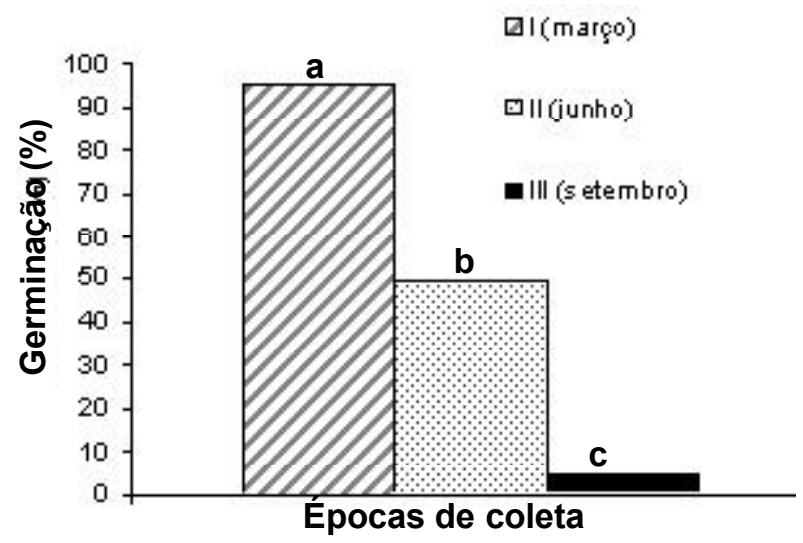

FIGURA 2. Valores médios de percentagem de germinação de sementes de $A$. gratissima coletadas em três épocas diferentes (março, junho e setembro) no ano de 2006. ${ }^{* *}$ Médias seguidas da mesma letra minúscula não diferem estatisticamente entre si, pelo teste $F$ (Tukey) $(p<0,05)$. Teste de Tetrazólio $(T Z)>85 \%$.
Conforme Rosa \& Ferreira (2001), a percentagem de germinação de $A$. gratissima em areia foi de $34 \%$, em BOD, com temperatura alternada de 20-30 ${ }^{\circ} \mathrm{C}$, diferindo do índice de emergência verificado em casa-de-vegetação ( $87 \%$ ) com temperatura entre 15 e $29^{\circ} \mathrm{C}$.

O tipo de substrato utilizado para a produção de mudas de alfazema-do-brasil foi estatisticamente diferente quanto ao aspecto da germinação, porém, quando se observa o efeito do substrato no desenvolvimento inicial da espécie, verifica-se uma situação crítica nesse desenvolvimento indicando uma dependência nutricional das sementes no início de seu crescimento (Tak

No parâmetro de crescimento das plântulas de $A$. gratissima, os maiores resultados foram observados no cultivo com substrato comercial (Plantmax ${ }^{\circledR}$ ). Para número de folhas e comprimento da raiz principal, menores resultados foram observados para o substrato areia, para comprimento médio do par de folhas do segundo nó, comprimento do ramo e taxa de sobrevivência não houve diferença estatística entre casca de arroz carbonizada e areia, sendo inferiores estatisticamente ao Plantmax ${ }^{\circledR}$ (Tabela 1).

Observa-se que as plântulas obtidas por meio de sementes de $A$. gratissima semeadas em Plantmax ${ }^{\circledR}$ Hortaliça (substrato comercial), o qual proporciona boa disponibilidade de nutrientes para seu estabelecimento, apresentou maior ganho em todos os parâmetros avaliados (Tabela 1). Como a semente da espécie é minúscula (pouca reserva), é essencial para o seu desenvolvimento e crescimento um incremento nutricional nos estágios iniciais.

Após 35 dias, as plântulas provenientes do substrato comercial se mostraram mais vistosas e

TABELA 1. Valores médios de percentagem de germinação para sementes de $A$. gratissima e parâmetros de crescimento para a plântula em número de folhas (NF) (par), comprimento médio de folha (par) do segundo nó (CF), comprimento do ramo (Cro) e comprimento da raiz principal (CR) submetidos a três substratos. Taxa de sobrevivência (TS) de plântulas provenientes dos três substratos estudados, quando transferidas para copo plástico com Plantmax ${ }^{\circledR}$, após 30 dias. UFLA, Lavras, MG, 2007.

\begin{tabular}{|c|c|c|c|c|c|c|}
\hline \multirow{2}{*}{ Substratos } & \multirow{2}{*}{$\begin{array}{c}\text { Análise de } \\
\text { germinação }\end{array}$} & \multicolumn{4}{|c|}{ Parâmetros de crescimento } & \multirow{2}{*}{$\begin{array}{l}\text { TS } \\
(\%)\end{array}$} \\
\hline & & NF & $\begin{array}{l}\mathrm{CF} \\
(\mathrm{cm})\end{array}$ & $\begin{array}{l}\text { Cro } \\
(\mathrm{cm})\end{array}$ & $\begin{array}{l}\mathrm{CR} \\
(\mathrm{cm})\end{array}$ & \\
\hline Plantmax $^{\circledR}$ & $93,25 \mathrm{ab}$ & $7,40 \mathrm{a}$ & $1,80 \mathrm{a}$ & $2,00 \mathrm{a}$ & $10,00 \mathrm{a}$ & $100 \mathrm{a}$ \\
\hline $\begin{array}{c}\text { Casca de arroz } \\
\text { carbonizada }\end{array}$ & $95,50 \mathrm{a}$ & $4,20 \mathrm{~b}$ & $1,00 \mathrm{~b}$ & $1,00 \mathrm{~b}$ & $6,40 \mathrm{~b}$ & $38 \mathrm{~b}$ \\
\hline Areia & $87,00 \mathrm{~b}$ & $2,80 \mathrm{c}$ & $0,40 \mathrm{~b}$ & $0,80 \mathrm{~b}$ & $4,80 \mathrm{c}$ & $25,5 \mathrm{~b}$ \\
\hline
\end{tabular}

${ }_{* \star}$ Médias seguidas da mesma letra na vertical, não diferem estatisticamente entre si, pelo teste de Tukey $(P<0,05)$. 
com maiores garantias de sobrevivência que as dos outros dois substratos, sendo verificada pela taxa de sobrevivência de $100 \%$ para tal substrato (Tabela 1 , Figura 3A).

Caron et al. (2004) encontraram resultados semelhantes para alface (Lactuca sativa), referente a valores de fitomassa quando comparados os substratos casca de arroz carbonizada e Plantmax ${ }^{\circledR}$, o qual mostrou melhores resultados, corroborando assim com o fato de que o tipo de substrato influencia na produção final das plântulas a partir de sementes.

Para a obtenção de plântulas de $A$. gratissima, a escolha do substrato poderia ser influenciado apenas pelo menor preço e disponibilidade, como é o caso da areia, facilmente encontrada e de menor custo para o produtor, porém, quando se observa o estabelecimento dessas plântulas frente aos substratos, observa-se que um substrato mais rico nutricionalmente proporciona plântulas maiores, com condições de atingirem a condição de mudas (Figura 3A).

A granulometria e o arranjo das partículas que formam o substrato são características importantes para definir na capacidade de retenção de água. A composição química do substrato é outra característica que pode influenciar na disponibilidade de nutrientes, influindo assim, no acúmulo de fitomassa da cultura (Caron et al., 2004).

Conforme Andrade et al. (2004), sementes de lichia (Litchi chinensis Sonn) necessitam de um substrato que permite melhores combinações de água e disponibilidade de oxigênio, como a areia lavada e casca de arroz carbonizada, pois é uma semente grande, com reserva de nutrientes para o desenvolvimento inicial, necessidade contrária ao da A. gratissima. Para as sementes de lichia, germinadas em temperatura constante de $25^{\circ} \mathrm{C} \mathrm{em}$ caixas plásticas, o percentual de germinação não diferiu significativamente entre areia lavada e casca de arroz carbonizada, 73,81 e $85,71 \%$, respectivamente, com 28 dias de observação.

Ainda para corroborar com a hipótese de que um substrato com incremento nutricional interfere positivamente no estabelecimento de mudas, quando as plântulas germinadas em sementeiras foram transferidas para copos de plástico de $200 \mathrm{~mL}$ com substrato comercial, nas mesmas condições, as plântulas provenientes do substrato comercial tiveram uma taxa de sobrevivência de $100 \%$, mas para as provenientes da sementeira com casca de arroz carbonizada e areia esterilizada, a taxa de sobrevivência foi de 38 e $26 \%$ respectivamente (Tabela 1 e Figura 3B).

A hipótese de que as sementes, por serem pequenas, não têm reservas nutricionais suficientes para garantir um desenvolvimento adequado, sendo que este desenvolvimento inicial é de fundamental
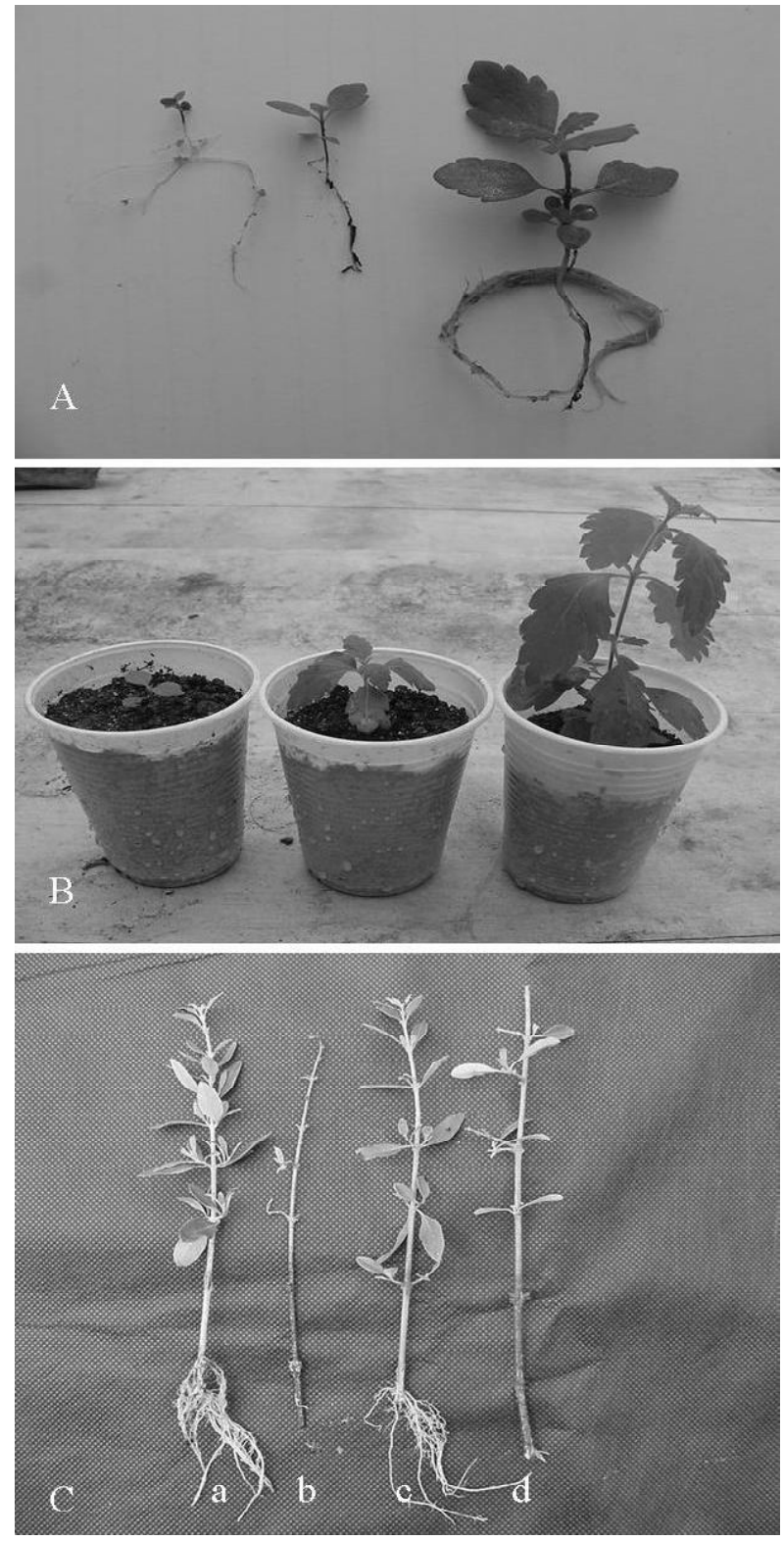

FIGURA 3. Plântulas de $A$. gratissima germinadas em três substratos (da esquerda para a direita, areia, casca de arroz carbonizada e Plantmax ${ }^{\circledR}$ (substrato comercial): após 35 dias da semeadura (A), com 20 dias de transplante para Plantmax ${ }^{\circledR}(B)$. Estaca herbácea $\mathrm{e}$ semilenhosa em areia (a e b) e Plantmax ${ }^{\circledR}$ (c e d) (C).

importância para o estabelecimento da planta, é confirmada. Apesar da casca de arroz carbonizada, ser utilizada como substrato devido sua estabilidade física e química, sendo mais resistente à decomposição e apresentar alta porosidade, tal como a areia, estes substratos não são indicados para obtenção de mudas de $A$. gratissima.

\section{Propagação assexuada - estaquia}

No ensaio para determinar o melhor tipo de estaca para enraizamento, a estaca herbácea foi 
superior em todos os parâmetros avaliados, apresentando um enraizamento de 96 e 95\% nos substrato comercial e na areia, respectivamente. A estaca herbácea foi usada com ápice caulinar, onde é fonte de auxina, infere-se que este melhor enraizamento seja devido esta fonte de auxina. Uma outra explicação pode ser devido à permanência das folhas na estaca herbácea, que é também uma fonte de auxina, e na estaca semilenhosa houve uma queda das folhas. Estacas semilenhosas mostraram uma percentagem de enraizamento de $26 \%$ no substrato areia, não apresentando desenvolvimento de raiz em substrato comercial (Tabela 2).

Para a produção de mudas de $A$. gratissima via estaquia, se observa que a estaca herbácea é estatisticamente superior a estaca semilenhosa. Para o tipo de substrato utilizado, o substrato comercial foi estatisticamente superior na percentagem de enraizamento e comprimento da raiz para a estaca herbácea. Quanto ao número de raiz e fitomassa seca da raiz, não houve diferença estatística para a estaca herbácea e o tipo de substrato. Quando se verifica o desenvolvimento de raízes em estaca semilenhosa, quanto à percentagem de enraizamento e comprimento da raiz, o substrato areia foi estatisticamente superior (Tabela 2 e Figura 3C).

Para estacas semilenhosas de Lippia alba, observa-se comportamento semelhante no enraizamento em diferentes substratos, não havendo diferença significativa quanto à percentagem de

TABELA 2. Parâmetro de crescimento para mudas de dois tipos estacas, herbácea $(\mathrm{H})$ e semilenhosa $(\mathrm{SL})$ de $A$. gratissima versus Plantmax ${ }^{\circledR}$ (substrato comercial) e areia, referentes a percentagem de enraizamento, comprimento da raiz, número de raiz e fitomassa seca da raiz (FSR). Lavras, MG, 2007.

\begin{tabular}{|c|c|c|c|c|c|c|c|c|}
\hline & \multicolumn{2}{|c|}{$\begin{array}{l}\text { Enraizamento } \\
(\%)\end{array}$} & \multicolumn{2}{|c|}{$\begin{array}{l}\text { Comprimento da Raiz } \\
\qquad(\mathrm{cm})\end{array}$} & \multicolumn{2}{|c|}{ Número de Raiz } & \multicolumn{2}{|c|}{$\begin{array}{l}\text { FSR } \\
(\mathrm{g})\end{array}$} \\
\hline & $\mathrm{H}$ & SL & $\mathrm{H}$ & SL & $\mathrm{H}$ & SL & $\mathrm{H}$ & SL \\
\hline Plantmax $®$ & $96 \mathrm{Aa}$ & $\mathrm{OBb}$ & $6,11 \mathrm{Aa}$ & $0,00 \mathrm{Bb}$ & $8,01 \mathrm{Aa}$ & $0,00 \mathrm{Bb}$ & $0,05 \mathrm{Aa}$ & $0,00 \mathrm{Ba}$ \\
\hline Areia & $95 \mathrm{Ab}$ & $26 \mathrm{Ba}$ & $3,99 A b$ & $1,15 \mathrm{Ba}$ & $7,40 \mathrm{Aa}$ & $3,70 \mathrm{Ba}$ & $0,05 \mathrm{Aa}$ & $0,03 \mathrm{Ba}$ \\
\hline
\end{tabular}

** Médias seguidas de maiúscula na horizontal, minúscula na vertical, não diferem estatisticamente entre si, pelo teste de ScottKnott $(p<0,05)$.

enraizamento, de brotação e número de brotos por estaca. Ocorreu diferença significativa quanto ao comprimento dos brotos, sendo o maior valor observado no substrato comercial (Plantmax ${ }^{\circledR}$ ) superior à vermiculita. Os substratos inorgânicos, como a vermiculita, possuem pouca reserva de nutrientes, o que pode ter causado esta resposta (Biasi \& Costa, 2003).

\section{CONCLUSÃO}

A germinação das sementes é maior nas temperaturas constantes de 20 e $25^{\circ} \mathrm{C}$ com 12 horas de fotoperíodo. A melhor época de coleta de sementes é em março. O substrato comercial proporcionou $100 \%$ de sobrevivência das plântulas. As estacas herbáceas apresentam maior percentagem de enraizamento em substrato comercial.

\section{AGRADECIMENTO financeiro.}

\section{REFERÊNCIA}

ANDRADE, R.A. et al. Influence of the Substrate in Germination of Lychee Seeds. Revista Brasileira de Fruticultura, v.26, n.2. p.375-6, 2004.

BASKIN, C.C.; BASKIN, J.M. Seeds: ecology, biogeography and evolution of dormancy and germination. London: Academic Press, 2001. 666p.

BEZERRA, J.E.F.; LEDDERMAN, I.E. Propagação vegetativa por estaquia da aceroleira. In: _.. Acerola no Brasil, produção e mercado. Vitória da Conquista: UESB. 1995. p.32-40.

BIASI, L.A.; COSTA, G. Propagação vegetativa de Lippia alba. Ciência Rural, v.33, n.3, p.455-9, 2003.

BRASIL. Ministério da Agricultura. Regras para análise de sementes. Brasília: Governo do Brasil, Ministério da Agricultura, 1992. 365p.

CARON, B.O. et al. Crescimento da alface em diferentes substratos. Revista de Ciências Agroveterinárias, v.3, n.2, p.97-104, 2004.

FERREIRA, D.F. SISVAR 4. 3- Sistema de analises estatísticas. Lavras: UFLA/DEX, 1999.

HARTMANN, N.T. et al. Plant propagation: principles and practices. 7.ed. New Jersey: Prentice-Hall, 2002. 880p.

PINTO, J.E.B.P. et al. Aspectos morfofisiológicos e conteúdo de óleo essencial de plantas de alfazemado-brasil em função de níveis de sombreamento. Revista Brasileira de Horticultura, v.25, n.2, p.210- 
4, 2007.

ROSA, S.G.T.; FERREIRA, A.G. Germinação de sementes de plantas medicinais lenhosas. Acta Botânica Brasílica, v.15, n.2, p.147-54. 2001.

SILVA, M.C.C. Fenologia, maturação fisiológica e aspectos da germinação de sementes de Platymiscium floribundum Vog. no Parque Estadual
Alberto Löfgren, Instituto Florestal, São Paulo - SP. 2005. 126p. Tese (Doutorado em Ecologia e Recursos Naturais)Universidade Federal de São Carlos, São Paulo. SOUZA, A.A. et al. Aloysia gratissima (Gill et Hook) Tronc. (garupá, erva santa): uso popular e perspectivas na pecuária ecológica. Revista Brasileira de Agroecologia, v.2, n.1, p.725-8, 2007. 